\title{
Yapay Sinir Ağları Kullanarak Türkiye Traktör Satış Adedinin Tahmin Edilmesi
}

\author{
Çağdaş Civelek ${ }^{1 *}$ \\ 1* Çukurova Üniversitesi, Ziraat Fakültesi, Tarım Makinaları ve Teknolojileri Mühendisliği Bölümü, Adana, Türkiye, (ORCID: 0000-0002-3669-488X), \\ ccivelek@cu.edu.tr
}

(İlk Geliş Tarihi 26 Eylül 2021 ve Kabul Tarihi 23 Aralık 2021)

(DOI: 10.31590/ejosat.1000964)

\begin{abstract}
ATIF/REFERENCE: Civelek, Ç. (2021). Yapay Sinir Ağları Kullanarak Türkiye Traktör Satış Adedinin Tahmin Edilmesi. Avrupa
\end{abstract} Bilim ve Teknoloji Dergisi, (31), 375-381.

\section{Öz}

Traktör satış tahmini, traktör üreticileri ve bayileri açısından gelecek dönemdeki planlamaların yapılması açısından büyük önem taşımaktadır. Satış tahmini pek çok değişkene bağlı olması sebebi ile oldukça zor bir problemdir. Günümüzde ise yapay sinir ağları yöntemleri ile geçmişe dönük verilerden yola çıkılarak tahmin gerçekleştirilebilmektedir. Bu çalışmada 2016-2019 yılları arasındaki seçilmiş veriler kullanılarak yapay sinir ağları ile gerçekleştirilen analizlerle traktör satış tahmini gerçekleştirilmiştir. İleri beslemeli geri yayılım yapay sinir ağı metodu kullanılarak 2 ve 3 katmanlı olarak gerçekleştirilen test sonuçlarına göre en iyi tahminin LOGSIG transfer fonksiyonunun kullanıldığı 3 katmanlı, 1. ara katmanında 2 ve 2. ara katmanında 4 nöron bulunan yapay sinir ağı tipinde en iyi sonucu verdiği belirlenmiştir.

Anahtar Kelimeler: Tarım Traktörleri, Traktör Satış Tahmini, Yapay Sinir Ağları.

\section{Tractor Sales Forcasting for Turkey Using Artificial Neural Network}

\begin{abstract}
Tractor sales forecasting has a high importance for tractor manufacturers and dealers for future planning. However, sales forecasting is not an easy problem to be solved. Nowadays, by using artificial neural networks tools future predictions could be made using past data. In this study using selected past data from 2016 to 2019, tractor sales forecasting was predicted using artificial neural network. Using feed-forward back propagation for 2 and 3 layered neural networks, it was found out that the best prediction was obtained by using LOGSIG transfer function for 3-layered artificial neural network with 2 neurons in the first layer and 4 neurons in the second layer.
\end{abstract}

Keywords: Agricultural Tractors, Tractor Sales Forecasting, Artificial Neural Networks.

*Sorumlu Yazar: ccivelek@cu.edu.tr 


\section{Giriş}

Türkiye'deki traktör sayısı son 20 y1l içerisinde nerede ise 2 kat artarak 2000 yılında 1159 070'ten, 2020 yılında 1958 727'ye ulaşmıştır. 2004-2014 yılları arasındaki son 10 yılda her yıl için trafiğe kaydedilen traktör sayısı17 bin ile 62 bin arasında sürekli değişkenlik gösterirken, trafikten kaydı silinen traktör sayısı ise yıllık 1000 ile 3000 arasında değişmektedir (Civelek, 2016). Bir sonraki yıl satılması beklenen traktör sayısının tahmin edilebilmesi traktör ve yedek parça üreticileri ile diğer yan sanayi parça üreticileri ve traktör bayilerinin ileriye dönük satış ve satış sonrası planlamalarını yapabilmeleri açısından büyük önem taşımaktadır. Satış, özellikle de traktör satış tahmini pek çok ekonomik değişkeni içerisinde barındırması sebebi ile çözülmesi pek de kolay olmayan problemlerden biri olarak karşımıza çıkmaktadır.

Tarım, iklim ve ekonomik koşullardan oldukça etkilenen bir üretim alanıdır. $\mathrm{Bu}$ iki koşulun tek başına veya birlikte olumlu veya olumsuz yönde ilerlemesi kisa vadede etkisini hızla göstermekte, buna bağlı olarak ilk olarak üretici son olarak da son kullanıcı tarafında etkisini hızla göstermektedir. $\mathrm{Bu}$ nedenle çiftçinin traktör ve tarım alet-makine talebinin yıl içerisinde ve yıllar arasında hızlı bir değişikliğe uğraması mümkündür.

Satış tahmininde en çok kullanılan yöntemler zaman serileri analizi ve karma yöntemler olarak ikiye ayrılabilir. En çok kullanılan tahmin metotları olarak çoklu lineer regresyon, çoklu lineer olmayan regresyon, otoregresif entegre hareketli ortalama modeli (autoregressive integrated moving average, ARIMA) ve yapay sinir ağları karşımıza çıkmaktadır. Satış tahminine yönelik olarak geçmişe dönük yapılan literatür taramasında ise traktör ve otomotiv sektörüne ait tahmin çalışmalarında ARIMA ve yapay sinir ağı modellerinin kullanıldığ

Biondi ve ark. (1998) İtalya, Fransa ve Amerika için basit traktör talep tahmin modellerini tek değişkenli ve çok değişkenli olarak iki farklı yöntemle geliştirmişlerdir. Tek değişkenli modellerinde ARIMA, çok değişkenli modellerinde ise çiftlik değeri, traktör fiyat indeksi, traktör stoğu ve bir önceki yılın traktör talebi olan değişkenlerden yararlanarak dinamik regresyon modeli kullanmışlardır. Sonuç olarak ARIMA modelinin, çok değişkenli modellerle aynı istatistiksel doğruluğa sahip olduğunu belirlemişler, traktör tahmin modellerinin kısa periyotlar için düşük hata derecesine sahip olduğunu, uzun periyotlar için yapılan tahminlerde ise tahmin hatalarının artmasına bağlı olarak arttığını açıklamışlardır.

Unakıtan ve Akdemir (2007) ARIMA modeli kullanarak Türkiye traktör talebinin belirlenmesi üzerine gerçekleştirdikleri çalışmada, 1961-2003 yılları arasındaki FAO'nun (Food and Agriculture Organization) verilerinden yararlanmışlardır. Bağımsız değişkenler olarak kümülatif sermaye, sermaye büyüme oranı, üretim, ihracat ve ithalat verilerinden yararlanarak ileri yıllardaki traktör talebini tahmin etmişler, 2015 yılında yıllık talebin 15000 adede ulaşacağı ve toplam traktör sayısı artış oranının tarım kesiminde çalışan sayısının azalmasına bağlı olarak azalacağını belirtmişlerdir.

Karaatlı ve ark. (2012), yapay sinir ağları kullanarak otomobil satış adedinin ileriki yıllara dönük tahmin edilmesi üzerine gerçekleştirdikleri çalışmada, 2007-2011 yılları arasındaki 7 farklı bağımsız değişkenden yararlanarak yapay sinir ağı kurmuşlar ve 1. ara katmanında 4, 2. ara katmanında 3 nöron olan 3 ara katmanlı yapay sinir ağının \%16.82 MAPE (mean e-ISSN: 2148-2683 absolute percentage error) değeri ile en iyi sonucu verdiğini belirlemişlerdir.

Efendigil ve ark. (2009) talep tahmini yapan bir karar destek sisteminde yapay sinir ağları ile bulanık mantık modellerini karşılaştırmışlardır. Dayanıklı tüketim malları üzerine yaptıkları çalışmada toplam 24 aylık birim satış fiyatı, ürün kalitesi, müşteri tatmin derecesi, promosyonların etki derecesi verilerini bağımsız, talep miktarını bağımlı değişken olarak kullanmışlardır. Yapay sinir ağı ve bulanık mantık modellerine uygulanan çift taraflı metodunun daha düşük MAPE değeri sunarak, bulanık mantık modelinde yapay sinir ağı modellerine göre daha iyi sonuç verdiğini belirlemişlerdir.

Yapay sinir ağları, yapay zekâ ve makine öğrenmesinin bir kombinasyonu olarak tanımlanmıştır (Gurjar ve Patel, 2021). Biyolojik sinir ağları, birbirine bağlı nöronlardan oluşmaktadır. Sinirsel aktiviteler ise, bir nöronda oluşan aktivitenin elektrokimyasal değişimlerle diğer nörona geçmesi ile gerçekleşir. Bir nöron ise, birden çok nöronla temas kurabilmektedir fakat, her bağlantının haberleşme önceliği eşit değildir. Yapay sinir ağları temel yapısını biyolojik sinir ağlarından almaktadır (Graupe, 2013). Yapay sinir ağları basit ve çok katmanlı olmak üzere temel olarak iki farklı kategoriye ayrılmaktadır. Basit yapay sinir ağları Perceptron, Artron, Adaline, Madaline olarak 3'e, çok katmanlı sinir ağları ise Geri Yayılım, Hopfield, Karşı Yayılma ve Lamstar olmak üzere 4'e ayrılmaktadır. Hazırlanan bu çalışmada ise, 1968 yılında Rumelhart, Hinton ve Williams tarafından geliştirilen ve ara katmanlardaki nöronların ağırlıklarının ayarlanmasına imkân tanıyan geri yayılım modeli kullanılmıştır.

\section{Materyal ve Metot}

Traktör talebi tahmin modeli için bağımlı değişken olarak 2016-2019 yılları arasında trafiğe kaydı yapılan traktör sayısı (TKTS) (Türkiye İstatistik Kurumu, 2021a), bağımsız değişkenler olarak kişi başı gayri safi yurtiçi hasıla (GSYH - tarım, orman ve balıkçılık) (Türkiye Cumhuriyeti Merkez Bankası, 2021), dolar fiyatı (D) (Türkiye Cumhuriyeti Merkez Bankası, 2021), tarımsal girdi fiyat endeksi (TGFE) (Türkiye İstatistik Kurumu, 2021b), reel kesim güven endeksi (RKGE) (Türkiye Cumhuriyeti Merkez Bankası, 2021), ulaştırma ve haberleşme harcamaları (UHH) (Türkiye Cumhuriyeti Merkez Bankası, 2021), tüketim harcamaları (TH) (Türkiye Cumhuriyeti Merkez Bankası, 2021), taşıt kredileri (TK) (Türkiye Cumhuriyeti Merkez Bankası, 2021) kullanılmıştır (Tablo 1). Trafiğe kaydı yapılan traktör sayısı ve tarımsal girdi fiyat endeksi değerleri Türkiye İstatistik Kurumu veri tabanlarından, diğer veriler ise Türkiye Cumhuriyeti Merkez Bankası veri tabanlarından elde edilmiştir.

Kullanılan veriler SPSS programı kullanılarak DurbinWatson testine tabi tutulmuş, hata terimlerinin otokorelasyon değerleri incelenmiş ve Durbin-Watson test sonucu 1.542 bulunmuştur. Sonucun 1.5 ile 2.5 arasında olması verilerden elde edilen hata terimlerinin rastlantısal olduğunu göstermiştir. $\mathrm{Bu}$ sonuca göre kullanılan verilerden yola çıkılarak yapay sinir ağları ile traktör satışlarının tahmin edilebileceği anlaşılmıştır.

Veriler MATLAB R2019b yazılımında yapay sinir ağları ile tahmin modellerinin kurulabilmesi için Eşitlik 1 kullanılarak normalize edilmiştir (Yavuz ve Deveci, 2012).

$$
X^{\prime}=\frac{X-X_{\min }}{X_{\max }-X_{\min }}
$$


Formülde $\mathrm{X}^{\prime}$ verinin normalize hali, $\mathrm{X}$ gerçek veri, $\mathrm{X}_{\min }$ veri setindeki en küçük değer ve $X_{\max }$ veri setindeki en büyük değerdir.

Çalışma MATLAB yazılımının içerisinde yer alan yapay sinir ağları araç takımı (nntool) kullanılarak gerçekleştirilmiştir. Testlerde daha önceden belirlenen iki ve üç ara katmanlı yapay sinir ağları için ileri beslemeli geri yayılım metodu (feed-forward backprop) kullanılmıştır. Eğitim fonksiyonu olarak LevenbergMarquardt, öğrenme fonksiyonu olarak LEARNGDM ve performans ölçütü olarak MSE (hata ortalamalarının karekökü) kullanılmıştır. İki katmanlı yapay sinir ağlarında ara katmanda 6 nöron ve çıkış katmanında 1 nöron bulunmaktadır. Üç katmanlı yapay sinir ağında ise ara katmanlarda 2 ve 4, 4 ve 3 nöron olacak şekilde test aşamaları planlanmıştır. Her test aşaması için logaritmik sigmoid (LOGSIG), doğrusal (PURELIN) ve tanjant sigmoid (TANSIG) transfer fonksiyonları için tekrar edilmiştir (Tablo 2). Her bir yapay sinir ağı eğitimi tamamlandıktan sonra elde edilen ağa 2020 yılına ait 7 farklı değişkenin sisteme tanımlanması ile 2020 yılı traktör satış tahmin sayıları elde edilmiştir (Tablo 3).
Elde edilen veriler 2020 yılı gerçek satış rakamları ile karşılaştırılmıştır. Gerçek ve tahmin edilen satış rakamları RMSE (hata kareleri ortalamasının karekökü) (Eşitlik 2) ve MAPE (mutlak hata oranları ortalaması) (Eşitlik 3) değerlerinin Excel programında hesaplanması ile karşılaştırılmıştır.

$$
\mathrm{RMSE}=\sqrt{\frac{\sum\left(y_{i}-y_{p}\right)^{2}}{\mathrm{n}}}
$$

$\mathrm{MAPE}=\frac{1}{\mathrm{n}} \sum_{i=1}^{n}\left(\frac{\left|y_{i}-y_{p}\right|}{y_{i}}\right)$

Eşitlik 2 ve 3’te;

$\mathrm{y}_{\mathrm{i}}$ : gerçek değer,

$\mathrm{y}_{\mathrm{p}}$ : tahmin edilen değer,

n: örnek sayısıdır.

Tablo 1. Bă̆ımsız Değişkenlerin 2016-2019 Yılları Arasına Ait Değerleri

\begin{tabular}{|c|c|c|c|c|c|c|c|c|c|}
\hline Yll & Ay & $\begin{array}{c}\text { GSYH } \\
(\mathrm{T}, \mathrm{O}, \mathrm{B})\end{array}$ & D & TGFE & RKGE & UHH & TH & TK & TKTS \\
\hline \multirow{12}{*}{2016} & 1 & 1430162.30 & 3.00 & 103.52 & 103.20 & 12956.90 & 107972.40 & 29.00 & 3901 \\
\hline & 2 & 1430162.30 & 2.94 & 103.52 & 104.60 & 13224.50 & 109722.70 & 262.00 & 4915 \\
\hline & 3 & 1430162.30 & 2.89 & 103.52 & 107.20 & 13339.70 & 110740.70 & 355.00 & 7361 \\
\hline & 4 & 2204806.91 & 2.83 & 103.52 & 110.50 & 13353.00 & 112715.80 & 682.00 & 6835 \\
\hline & 5 & 2204806.91 & 2.92 & 103.52 & 110.20 & 13443.70 & 113581.70 & 1515.00 & 6810 \\
\hline & 6 & 2204806.91 & 2.91 & 103.52 & 107.70 & 13403.80 & 114288.40 & 4755.00 & 5724 \\
\hline & 7 & 2467751.80 & 2.96 & 103.52 & 108.00 & 13515.80 & 114626.90 & 7825.00 & 3992 \\
\hline & 8 & 2467751.80 & 2.96 & 103.52 & 102.20 & 13463.10 & 113533.60 & 17832.00 & 5410 \\
\hline & 9 & 2467751.80 & 2.96 & 103.52 & 106.10 & 13707.90 & 115266.70 & 27401.00 & 5120 \\
\hline & 10 & 2222619.88 & 3.07 & 103.52 & 101.00 & 13744.90 & 116007.20 & 34938.00 & 7544 \\
\hline & 11 & 2222619.88 & 3.27 & 103.52 & 103.50 & 13630.20 & 116493.40 & 43079.00 & 7224 \\
\hline & 12 & 2222619.88 & 3.49 & 103.52 & 97.60 & 13858.70 & 117528.30 & 49818.00 & 7761 \\
\hline \multirow{12}{*}{2017} & 1 & 1574123.34 & 3.73 & 113.09 & 97.10 & 14037.50 & 119388.60 & 57371.00 & 4222 \\
\hline & 2 & 1574123.34 & 3.67 & 113.09 & 105.90 & 13965.40 & 119602.50 & 66248.00 & 5180 \\
\hline & 3 & 1574123.34 & 3.66 & 113.09 & 108.90 & 13874.20 & 120739.80 & 77426.00 & 7073 \\
\hline & 4 & 2465987.34 & 3.65 & 113.09 & 111.20 & 13934.70 & 121806.60 & 89263.00 & 7067 \\
\hline & 5 & 2465987.34 & 3.56 & 113.09 & 109.20 & 13960.30 & 122815.00 & 102125.00 & 7345 \\
\hline & 6 & 2465987.34 & 3.52 & 113.09 & 112.40 & 13875.50 & 123266.20 & 115805.00 & 5657 \\
\hline & 7 & 2790059.11 & 3.56 & 113.09 & 109.50 & 14599.50 & 124346.60 & 128308.00 & 5321 \\
\hline & 8 & 2790059.11 & 3.51 & 113.09 & 110.70 & 14679.50 & 123882.00 & 147871.00 & 4610 \\
\hline & 9 & 2790059.11 & 3.47 & 113.09 & 111.60 & 14719.40 & 125860.20 & 160834.00 & 6267 \\
\hline & 10 & 2613656.72 & 3.66 & 113.09 & 109.50 & 14814.20 & 128719.80 & 179969.00 & 7932 \\
\hline & 11 & 2613656.72 & 3.88 & 113.09 & 106.30 & 14949.10 & 130467.60 & 201733.00 & 7605 \\
\hline & 12 & 2613656.72 & 3.85 & 113.09 & 103.30 & 14968.00 & 130516.70 & 213287.00 & 7514 \\
\hline \multirow{12}{*}{2018} & 1 & 1906258.77 & 3.77 & 136.04 & 108.30 & 15572.00 & 132146.60 & 223064.00 & 4679 \\
\hline & 2 & 1906258.77 & 3.78 & 136.04 & 110.80 & 15364.60 & 133191.10 & 244236.00 & 4497 \\
\hline & 3 & 1906258.77 & 3.88 & 136.04 & 111.90 & 15503.70 & 134645.60 & 270142.00 & 6302 \\
\hline & 4 & 2959864.52 & 4.05 & 136.04 & 111.20 & 15651.00 & 136786.90 & 293949.00 & 5639 \\
\hline & 5 & 2959864.52 & 4.41 & 136.04 & 109.90 & 15746.50 & 137949.50 & 330769.00 & 4923 \\
\hline & 6 & 2959864.52 & 4.62 & 136.04 & 104.60 & 15865.60 & 140553.30 & 344849.00 & 3425 \\
\hline & 7 & 3397009.81 & 4.74 & 136.04 & 102.70 & 15867.60 & 141338.40 & 361834.00 & 4015 \\
\hline & 8 & 3397009.81 & 5.73 & 136.04 & 96.40 & 16193.40 & 145750.60 & 362139.00 & 2836 \\
\hline & 9 & 3397009.81 & 6.36 & 136.04 & 89.60 & 16406.70 & 153022.70 & 305713.00 & 3793 \\
\hline & 10 & 3011425.22 & 5.86 & 136.04 & 87.60 & 16421.10 & 157609.90 & 159146.00 & 3913 \\
\hline & 11 & 3011425.22 & 5.37 & 136.04 & 92.80 & 16007.30 & 156883.90 & 153262.00 & 3725 \\
\hline & 12 & 3011425.22 & 5.30 & 136.04 & 91.50 & 15888.80 & 157115.50 & 150557.00 & 4224 \\
\hline
\end{tabular}




\begin{tabular}{|c|c|c|c|c|c|c|c|c|c|}
\hline \multirow{12}{*}{2019} & 1 & 2414931.92 & 5.37 & 156.99 & 93.00 & 16226.90 & 159046.30 & 148404.00 & 1506 \\
\hline & 2 & 2414931.92 & 5.26 & 156.99 & 97.20 & 16222.00 & 160808.10 & 152790.00 & 1582 \\
\hline & 3 & 2414931.92 & 5.44 & 156.99 & 102.10 & 16409.30 & 161515.00 & 161942.00 & 2359 \\
\hline & 4 & 3723901.95 & 5.73 & 156.99 & 105.50 & 16798.30 & 165662.80 & 168681.00 & 2482 \\
\hline & 5 & 3723901.95 & 6.05 & 156.99 & 98.90 & 17108.10 & 167515.10 & 186710.00 & 2685 \\
\hline & 6 & 3723901.95 & 5.81 & 156.99 & 102.50 & 16850.20 & 167321.80 & 195412.00 & 1878 \\
\hline & 7 & 4144388.81 & 5.67 & 156.99 & 98.30 & 16925.50 & 167818.30 & 207512.00 & 2558 \\
\hline & 8 & 4144388.81 & 5.62 & 156.99 & 102.50 & 16793.40 & 169192.70 & 215421.00 & 1942 \\
\hline & 9 & 4144388.81 & 5.71 & 156.99 & 98.80 & 18128.60 & 172809.40 & 211578.00 & 2642 \\
\hline & 10 & 3635683.00 & 5.78 & 156.99 & 100.90 & 18140.90 & 174773.20 & 209701.00 & 3145 \\
\hline & 11 & 3635683.00 & 5.73 & 156.99 & 102.00 & 18114.10 & 174668.00 & 207023.00 & 3321 \\
\hline & 12 & 3635683.00 & 5.83 & 156.99 & 103.60 & 18077.90 & 176015.60 & 203997.00 & 4120 \\
\hline
\end{tabular}

Tablo 2. MATLAB test aşamalarl

\begin{tabular}{|c|c|c|c|}
\hline Test Aşamaları & $\begin{array}{l}2 \text { katman } \\
6: 1 \text { nöron }\end{array}$ & $\begin{array}{c}3 \text { katman } \\
\text { 2:4:1 nöron }\end{array}$ & $\begin{array}{c}3 \text { katman } \\
\text { 4:3:1 nöron }\end{array}$ \\
\hline 1 & LOGSIG fonksiyonu & LOGSIG fonksiyonu & LOGSIG fonksiyonu \\
\hline 2 & PURELIN fonksiyonu & PURELIN fonksiyonu & PURELIN fonksiyonu \\
\hline 3 & TANSIG fonksiyonu & TANSIG fonksiyonu & TANSIG fonksiyonu \\
\hline
\end{tabular}

Tablo 3. 2020 Yılı Traktör Satış Tahmininde Kullanılan Veriler

\begin{tabular}{c|c|c|c|c|c|c|c|c}
\hline Yll & Ay & $\begin{array}{c}\text { GSYH } \\
(\mathbf{T , O}, \mathbf{B})\end{array}$ & D & TGFE & RKGE & UHH & TH & TK \\
\hline \multirow{6}{*}{2020} & 1 & 2875145.20 & 5.93 & 164.31 & 104.10 & 18075.30 & 178405.00 & 206634.00 \\
\cline { 2 - 9 } & 2 & 2875145.20 & 6.06 & 165.09 & 106.90 & 19846.70 & 182451.90 & 204746.00 \\
\cline { 2 - 9 } & 3 & 2875145.20 & 6.33 & 165.30 & 99.70 & 19298.50 & 182867.20 & 208630.00 \\
\cline { 2 - 9 } & 4 & 4204511.00 & 6.83 & 166.60 & 66.80 & 19275.10 & 183545.50 & 218256.00 \\
\cline { 2 - 9 } & 5 & 4204511.00 & 6.96 & 167.61 & 76.90 & 21085.00 & 188413.60 & 239737.00 \\
\cline { 2 - 9 } & 7 & 4204511.00 & 6.82 & 167.89 & 92.60 & 20580.60 & 189467.40 & 258581.00 \\
\cline { 2 - 9 } & 8 & 4919450.50 & 6.86 & 168.92 & 100.70 & 20750.00 & 191094.80 & 278580.00 \\
\cline { 2 - 9 } & 10 & 49450.50 & 7.27 & 171.34 & 106.20 & 20568.40 & 191775.70 & 294982.00 \\
\cline { 2 - 9 } & 11 & 4281907.92 & 8.02 & 185.92 & 103.90 & 20670.80 & 201208.90 & 389832.00 \\
\cline { 2 - 9 } & 12 & 4281907.92 & 7.73 & 190.98 & 106.80 & 20792.00 & 202059.80 & 412918.00 \\
\hline
\end{tabular}

\section{Araştırma Sonuçları ve Tartışma}

2016-2019 yılları arasındaki GSYH, D, TGFE, RKGE, UHH ve TH verilerinin MATLAB programında bağımsız değişkenler olarak tanımlanması ile 2 ve 3 ara katmanlı yapay sinir ağları oluşturulmuştur. Kurulan yapay sinir ağı modelleri eğitim modellerinin grafiksel gösterimi Şekil 1'de verilmiştir.

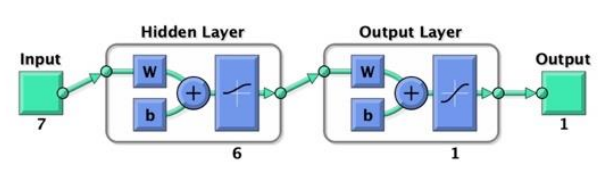

Ağ 1

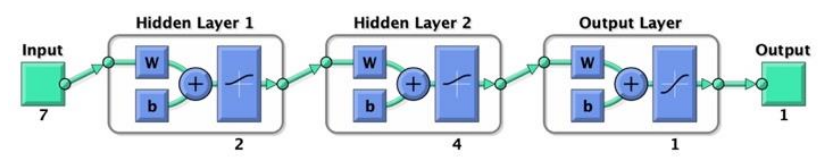

Ağ 2

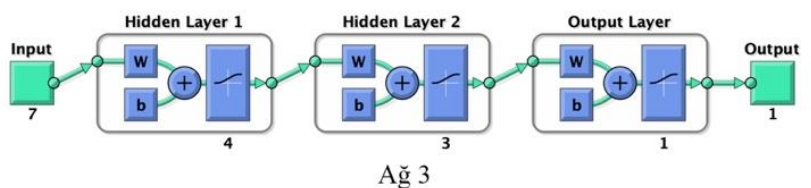

Ağ 3

Şekil 1. MATLAB yazılımında kurulan yapay sinir ağı modelleri 
Yapay sinir ağı eğitiminde kullanılan temel parametreler olarak, döngü sayısı (epochs) 1000 ve en fazla başarısız olma sayısı (max_fail) 100 olarak tanımlanmıştır (Şekil 2). Yapay sinir ağlarının eğitim performansları MSE (karelerin ortalamasının karekökü) ve R (korelasyon) katsayıları ile incelenmiştir. MSE değerleri sirası ile LOGSIG, PURELIN ve TANSIG transfer fonksiyonlarına göre $6: 1$ ağ için $0.0133,0.0164$ ve $0.0113 ; 2: 4: 1$ ağ 1 için $0.0157,0.0207$ ve $0.0179 ; 4: 3: 1$ ağ 1 için ise 0.0539 , 0.0182 ve 0.0117 olarak belirlenmiştir. Her üç ağ için belirlenen bu değerler eğitilen yapay sinir ağının 2016-2019 yılları arasındaki verileri iyi bir şekilde tahmin edebildiğini göstermektedir. R değerleri sirası ile LOGSIG, PURELIN ve TANSIG transfer fonksiyonlarına göre $6: 1$ ağ için $0.93,0.89$ ve $0.93 ; 2: 4: 1$ ağı için $0.92,0.89$ ve $0.94 ; 4: 3: 1$ ağı için ise $0.84,0.88$ ve 0.94 olarak hesaplanmıştır.

\begin{tabular}{|c|c|c|c|}
\hline & & Training Info & Traing Yaramerars \\
\hline showWindow & true & $\mathrm{mu}$ & 0.001 \\
\hline showCommandLine & false & mu_dec & 0.1 \\
\hline show & 25 & mu_inc & 10 \\
\hline epochs & 1000 & mu_max & 10000000000 \\
\hline time & Inf & & \\
\hline goal & 0 & & \\
\hline min_grad & $1 e-07$ & & \\
\hline max_fail & 100 & & \\
\hline
\end{tabular}

Şekil 2. Yapay sinir ağı eğitiminde kullanılan parametreler

Yapay sinir ağı eğitimlerinin tamamlanmasının ardından her bir yapay sinir ağ 1 için LOGSIG, PURELIN ve TANSIG transfer fonksiyonlarına göre simülasyonlar gerçekleştirilmiş ve normalize edilmiş satış sayıları elde edilmiştir. Normalize olarak elde edilen bu veriler, EXCEL yazılımında ters normalizasyon işlemine tabi tutularak tahmin edilen dönüştürülmüşs satış rakamları elde edilmiş (Tablo 4, 5, 6) ve elde edilen tahmini sayıların grafiksel gösterimi Şekil 3'te verilmiştir.

Yapay sinir ağlarından elde edilen verilerden yola çıkılarak EXCEL'de hesaplanan RMSE ve MAPE değerlerine ait sonuçlar Tablo 7'de verilmiştir. MAPE değerleri \%10'un altında olan modeller yüksek doğruluğa sahip, $\% 10$ ile $\% 20$ arasında olan modeller doğru tahminler, $\% 20$ ile $\% 50$ arasındaki modeller kabul edilebilir, \%50'den yüksek olan modeller ise hatalı modeller olarak sınıflandırılmaktadır (Witt and Witt, 1992; Tideswell ve ark., 2001).

Sonuçlar incelendiğinde 4:3:1 LOGSIG transfer fonksiyonu ile elde edilen sonuçların en düşük RMSE ve MAPE değerlerine sahip olduğu görülmektedir. Fakat Tablo 6 incelendiğinde, bu durumun 2020'nin tüm ayları için tahmin edilen traktör satış adetlerinin eşit çıkmasından kaynaklandığ 1 görülmüştür ve bu nedenle bu ağ en uygun tahmin ağı olmaktan elenmiştir. Geriye kalan yapay sinir ağı modelleri incelendiğinde ise 2:4:1 tipinde LOGSIG transfer fonksiyonu ile eğitilmiş modelin en iyi model olduğu belirlenmiştir. Bu modeli ise 6:1 TANSIG ağı \%38 MAPE değeri ile 2. ve 4:3:1 TANSIG ağı ise 38.6 MAPE değeri ile 3. olarak takip etmektedir.
Elde edilen sonuç, Karaatlı ve ark. (2012) tarafindan otomobil satış tahmini için geliştirilen yapay sinir ağında olduğu gibi 3 ara katmana sahip olması bakımından benzerlik göstermekle birlikte, \%38 olan MAPE değeri \%16.82'lik MAPE değeri ile karşılaştırıldığında daha düşük bir tahmin oranına sahiptir. Bu sonuçlara göre, bağımsız değişken sayısı ve tipinin değiştirilmesi ile daha iyi tahmin sonucu veren yapay sinir ağı modellerinin elde edilmesi mümkün olabilir.

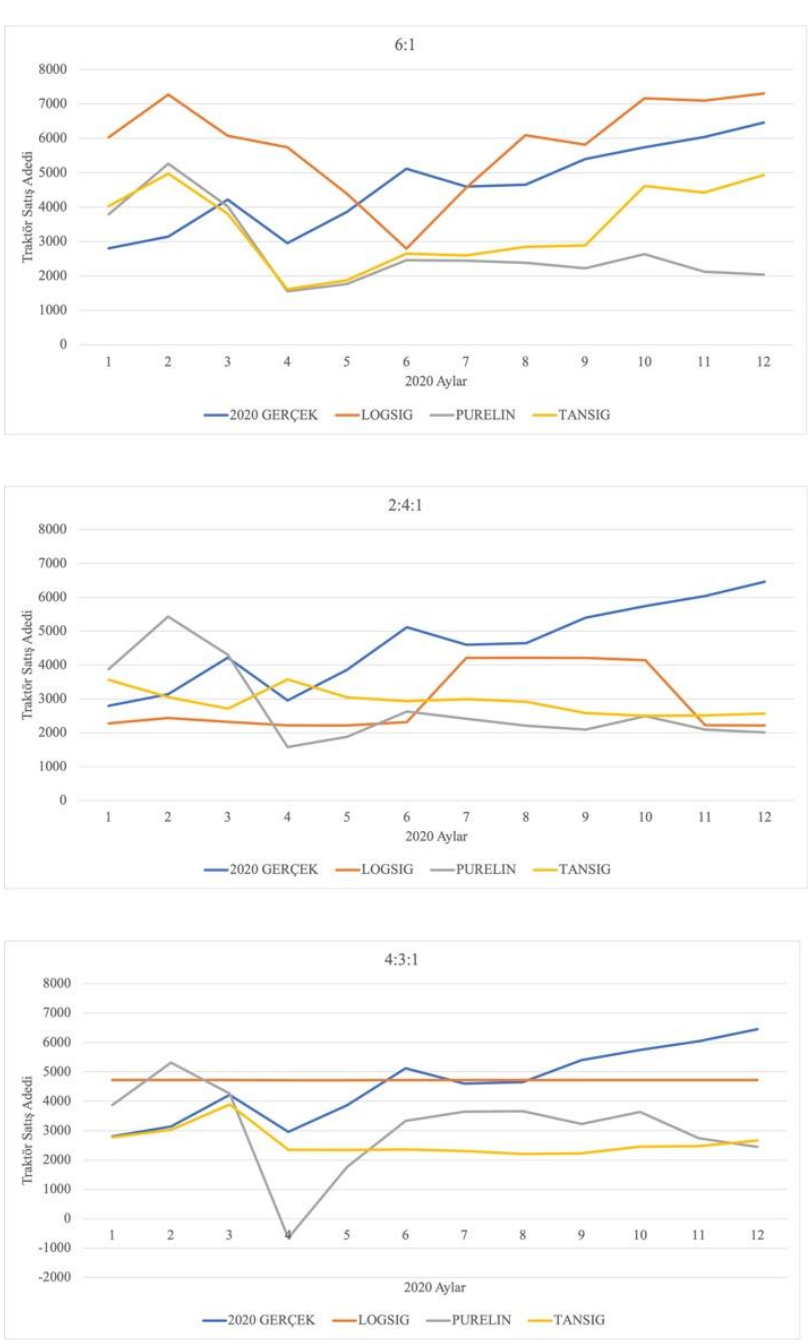

Şekil 3.3 farklı yapay sinir ağı ile elde edilmiş traktör satış tahminlerinin gerçek satış rakamları ile karşılaştırılması 
Avrupa Bilim ve Teknoloji Dergisi

Tablo 4. 2 Ara Katmanl, 6:1 Nöronlu Test Sonuçları

\begin{tabular}{|c|c|c|c|c|c|}
\hline \multirow[t]{2}{*}{ Yll } & \multirow[t]{2}{*}{ Ay } & \multirow[t]{2}{*}{$\begin{array}{c}\text { Gerçek Satıs } \\
\text { Rakamları }\end{array}$} & \multicolumn{3}{|c|}{$\begin{array}{c}2 \text { katman, 6:1 } \\
\text { Tahmini Satıș Rakamları }\end{array}$} \\
\hline & & & LOGSIG & PURELIN & TANSIG \\
\hline \multirow{12}{*}{2020} & 1 & 2800 & 6027 & 3790 & 4026 \\
\hline & 2 & 3141 & 7271 & 5264 & 4975 \\
\hline & 3 & 4220 & 6077 & 4023 & 3808 \\
\hline & 4 & 2956 & 5741 & 1555 & 1613 \\
\hline & 5 & 3860 & 4392 & 1769 & 1875 \\
\hline & 6 & 5117 & 2798 & 2456 & 2652 \\
\hline & 7 & 4596 & 4557 & 2444 & 2598 \\
\hline & 8 & 4648 & 6090 & 2384 & 2845 \\
\hline & 9 & 5396 & 5814 & 2222 & 2885 \\
\hline & 10 & 5744 & 7168 & 2635 & 4617 \\
\hline & 11 & 6038 & 7099 & 2122 & 4425 \\
\hline & 12 & 6456 & 7302 & 2038 & 4932 \\
\hline
\end{tabular}

Tablo 5. 3 Ara Katmanll, 2:4:1 Nöronlu Test Sonuçları

\begin{tabular}{|c|c|c|c|c|c|}
\hline \multirow[t]{2}{*}{ YII } & \multirow[t]{2}{*}{ Ay } & \multirow{2}{*}{$\begin{array}{c}\text { Gerçek Satış } \\
\text { Rakamları }\end{array}$} & \multicolumn{3}{|c|}{$\begin{array}{c}3 \text { katman, 2:4:1 } \\
\text { Tahmini Satış Rakamları }\end{array}$} \\
\hline & & & LOGSIG & PURELIN & TANSIG \\
\hline \multirow{12}{*}{2020} & 1 & 2800 & 2276 & 3879 & 3567 \\
\hline & 2 & 3141 & 2435 & 5430 & 3051 \\
\hline & 3 & 4220 & 2324 & 4304 & 2708 \\
\hline & 4 & 2956 & 2217 & 1577 & 3574 \\
\hline & 5 & 3860 & 2218 & 1882 & 3046 \\
\hline & 6 & 5117 & 2313 & 2626 & 2935 \\
\hline & 7 & 4596 & 4214 & 2410 & 2990 \\
\hline & 8 & 4648 & 4215 & 2209 & 2920 \\
\hline & 9 & 5396 & 4214 & 2092 & 2585 \\
\hline & 10 & 5744 & 4146 & 2493 & 2500 \\
\hline & 11 & 6038 & 2223 & 2093 & 2516 \\
\hline & 12 & 6456 & 2219 & 2009 & 2570 \\
\hline
\end{tabular}

Tablo 6. 3 Ara Katmanll, 4:3:1 Nöronlu Test Sonuçları

\begin{tabular}{|c|c|c|c|c|c|}
\hline \multirow[t]{2}{*}{ Yıl } & \multirow[t]{2}{*}{ Ay } & \multirow{2}{*}{$\begin{array}{c}\text { Gerçek Satış } \\
\text { Rakamları }\end{array}$} & \multicolumn{3}{|c|}{$\begin{array}{c}\text { 3 katman, 4:3:1 } \\
\text { Tahmini Satış Rakamları }\end{array}$} \\
\hline & & & LOGSIG & PURELIN & TANSIG \\
\hline \multirow{12}{*}{2020} & 1 & 2800 & 4719 & 3866 & 2777 \\
\hline & 2 & 3141 & 4719 & 5316 & 3028 \\
\hline & 3 & 4220 & 4719 & 4262 & 3885 \\
\hline & 4 & 2956 & 4719 & -652 & 2345 \\
\hline & 5 & 3860 & 4719 & 1754 & 2343 \\
\hline & 6 & 5117 & 4719 & 3334 & 2355 \\
\hline & 7 & 4596 & 4719 & 3643 & 2304 \\
\hline & 8 & 4648 & 4719 & 3660 & 2206 \\
\hline & 9 & 5396 & 4719 & 3230 & 2227 \\
\hline & 10 & 5744 & 4719 & 3632 & 2451 \\
\hline & 11 & 6038 & 4719 & 2737 & 2467 \\
\hline & 12 & 6456 & 4719 & 2445 & 2665 \\
\hline
\end{tabular}


Tablo 7. Yapay sinir ağları ile elde edilen verilerin RMSE ve MAPE değerlerinin kiyas tablosu

\begin{tabular}{c|c|c}
\hline $\begin{array}{c}\text { YAPAY SINİR AĞI } \\
\text { MODELLERİ }\end{array}$ & RMSE & MAPE \\
\hline $6: 1$ LOGSIG & 0.32 & 44.9 \\
\hline $6: 1$ PURELIN & 0.41 & 50.2 \\
\hline $6: 1$ TANSIG & 0.27 & 38.0 \\
\hline $2: 4: 1$ LOGSIG & 0.32 & 33.7 \\
\hline $2: 4: 1$ PURELIN & 0.42 & 51.0 \\
\hline $2: 4: 1$ TANSIG & 0.35 & 37.5 \\
\hline $4: 3: 1$ LOGSIG & 0.18 & 25.3 \\
\hline $4: 3: 1$ PURELIN & 0.36 & 46.3 \\
\hline $4: 3: 1$ TANSIG & 0.37 & 38.6 \\
\hline
\end{tabular}

\section{Sonuç}

Bu çalışmada tarımsal üretimde en büyük role sahip makine olan traktörün yapay sinir ağları ile satış tahmini modelleri geliştirilmiş ve LOGSIG transfer fonksiyonu ile elde edilen 3 katmanlı ve 1. ara katmanında 2, 2. ara katmanında ise 4 nöron bulunan yapay sinir ağında en iyi tahmin elde edilmiştir. Her ne kadar 3 ara katmanlı LOGSIG transfer fonksiyonuna sahip ve 1. ara katmanında 4,2 . ara katmanında 3 nöron bulunan yapay sinir ağı en iyi istatistiksel performansı gösterse de 2020 yılı için elde edilen traktör satış tahmin rakamlarının her ay eşit çıkması, bu ağın satış tahmininde kullanılmasına izin vermemektedir. $\mathrm{Bu}$ nedenle, yapay sinir ağları ile geliştirilen tahmin modellerinde istatistiksel analizlerin kullanılması her ne kadar yapay sinir ağının başarısını gösterse de bu analiz sonuçlarına her zaman güvenilmemesi gerektiği sonucunu ortaya koymuştur. Gerçekleştirilen çalışmada kullanılan bağımsız değişkenlerin örnek sayısının arttırılması, farklı bağımsız değişkenlerin yapay sinir ağına eklenmesi veya farklı yapay sinir ağı modellerinin kurulması, daha iyi traktör satış tahmin sayılarının elde edilmesini sağlayabilir. Fakat traktör satış tahmini, tarımın ekonomik, iklimsel, sosyopolitik ve benzeri pek çok faktöre bağlı olması sebebi ile çözülmesi zor olan bir problem özelliğini taşımaktadır.

\section{Kaynakça}

Biondi, P., Monarca, D., Panaro, A. (1998). Simple Forecasting Models for Farm Tractor Demand in Italy, France and the United States. Journal of Agricultural Engineering Research, 71, 25-35.

Civelek, Ç. (2016). Turkey's Demand for Agricultural Tractors. Scholars Journal of Agriculture and Veterinary Sciences, 3(1), 51-57.

Efendigil, T., Önüt, S., Kahraman, C. (2009). A Decision Support System for Demand Forecasting with Artificial Neural Networks and Neuro-fuzzy Models: A Comparative Analysis. Expert Systems with Applications, 36, 6697-6707.

Graupe, D. (2013). Principles of Artificial Neural Networks 3rd Adition. World Scientific Publishing Co. Pte. Ltd. ISBN: 978981-4522-73-1.

Gurjar, A. P., Patel, S. B. (2021). Fundamental Categories of Artificial Neural Networks. Applications of Artificial Neural Networks for Nonlinear Data. ISSN: 2327-0411.

Karaatlı, M., Ömürbek, N., Helvacioğlu, Ö. C., Tokgöz, G. (2012). Yapay Sinir Ağları ile Otomobil Satış Tahmini.
Uluslararası Yönetim İktisat ve İşletme Dergisi, 8 (17), 87-100.

Tideswell, C., Mules, T., Faulkner, B. (2001). An Integrative Approach to Tourism Forecasting: A Glance in the Rearview Mirror. Journal of Travel Research, 40, 162-171.

Türkiye Cumhuriyeti Merkez Bankası (2021). Gayri Safi Yurtiçi Hasıla (tarım, orman ve balıçılık). https://evds2.tcmb.gov.tr/index.php?/evds/. Son erişim tarihi: 20.08.2021.

Türkiye İstatistik Kurumu (2021a). Ulaştırma İstatistikleri. http://biruni.tuik.gov.tr/medas/?kn=89\&locale=tr Son erişim tarihi: 20.08 .2021

Türkiye İstatistik Kurumu (2021b). Tarım Ürünleri Üretici Fiyat Endeksi.

https://data.tuik.gov.tr/Bulten/DownloadIstatistikselTablo?p $=$ uDsTTT6Lfifu3AXY4r1UOsD3KWWIsD00yOhmJ/wBUt INPVwj4hCU6Cmg59WvDe/A Son erişim tarihi: 20.08.2021

Unakıtan, G., Akdemir, B. (2007). Tractor Demand Projection in Turkey. Biosystems Engineering, 97, 19-25.

Witt, S. F., Witt, C. A. (1992). Modelling and Forecasting Demand in Tourism. London: Academic Press, 195, ISBN-0127-60740-4.

Yavuz, S., Deveci, M. (2012). İstatistiksel Normalizasyon Tekniklerinin Yapay Sinir Ağın Performansına Etkisi. Erciyes Üniversitesi İktisadi ve İdari Bilimler Fakültesi Dergisi, 40, 167-187. 